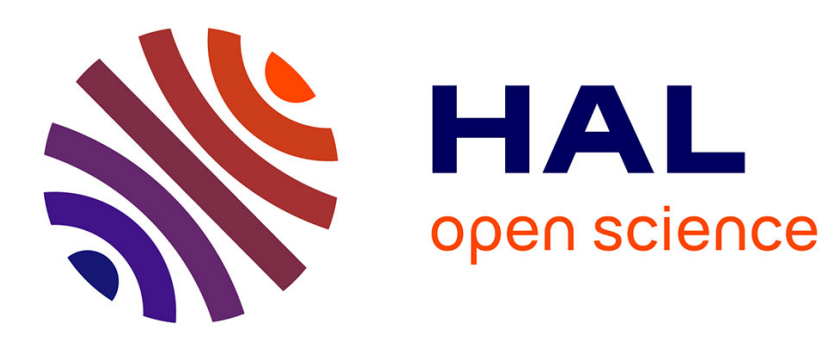

\title{
Characterization of reentrant cholesteric, cholesteric and chiral smectic phases of three recent polar mesogens
}

\author{
N. Isaert, G. Joly, C. Destrade, Nguyen Huu Tinh
}

\section{To cite this version:}

N. Isaert, G. Joly, C. Destrade, Nguyen Huu Tinh. Characterization of reentrant cholesteric, cholesteric and chiral smectic phases of three recent polar mesogens. Revue de Physique Appliquée, 1988, 23 (3), pp.273-279. 10.1051/rphysap:01988002303027300 . jpa-00245771

HAL Id: jpa-00245771

https://hal.science/jpa-00245771

Submitted on 1 Jan 1988

HAL is a multi-disciplinary open access archive for the deposit and dissemination of scientific research documents, whether they are published or not. The documents may come from teaching and research institutions in France or abroad, or from public or private research centers.
L'archive ouverte pluridisciplinaire HAL, est destinée au dépôt et à la diffusion de documents scientifiques de niveau recherche, publiés ou non, émanant des établissements d'enseignement et de recherche français ou étrangers, des laboratoires publics ou privés. 


\title{
Characterization of reentrant cholesteric, cholesteric and chiral smectic phases of three recent polar mesogens
}

\author{
N. Isaert $\left({ }^{1}\right)$, G. Joly $\left({ }^{1}\right)$, C. Destrade $\left({ }^{2}\right)$ and Nguyen Huu Tinh $\left({ }^{2}\right)$ \\ ${ }^{1}$ ) Laboratoire de Dynamique des Cristaux Moléculaires, U.A. CNRS n 801, Université des Sciences et \\ Techniques de Lille-Flandres-Artois, U.F.R. de Physique, 59655 Villeneuve d'Asq Cedex, France \\ $\left({ }^{2}\right)$ Centre de Recherches Paul Pascal, Domaine Universitaire, 33405 Talence Cedex, France
}

(Reçu le 7 avril 1987, révisé le 14 décembre 1987, accepté le 16 décembre 1987)

\begin{abstract}
Résumé. - L'article expose les variations du pas dans les phases torsadées de trois mésogènes polaires récents présentant du polymorphisme rentrant: $(\alpha) \mathrm{KN}_{\mathrm{re}}^{*} \mathrm{~S}_{\mathrm{A}} \mathrm{N}^{*} \mathrm{I} ;(\beta) \mathrm{KS}_{\mathrm{F}}^{*} \mathrm{~S}_{\mathrm{c}}^{*} \mathrm{~N}_{\mathrm{re}}^{*} \mathrm{~S}_{\mathrm{A}} \mathrm{N}^{*} \mathrm{I} ;(\gamma) \mathrm{S}_{\mathrm{A}} \mathrm{N}_{\mathrm{re}}^{*}$ $S_{\text {Are }} N^{*}$ I. Les valeurs obtenues confirment la divergence du pas à l'approche d'une phase $S_{A}$ et la divergence du pas à chaque extrémité d'une phase cholestérique comprise entre deux phases $S_{A}$ et $S_{A r e}$; le pas de la phase $\mathrm{S}_{\mathrm{c}}^{*}$ conserve une valeur finie aux transitions $\mathrm{S}_{\mathrm{c}}^{*}-\mathrm{N}_{\mathrm{re}}^{*}$ et $\mathrm{S}_{\mathrm{F}}^{*}-\mathrm{S}_{\mathrm{c}}^{*}$. Les mesures directes du pas par la méthode de Grandjean-Cano sont confirmées par l'étude de l'activité optique : la comparaison des résultats permet de décrire les variations de la biréfringence des diverses phases étudiées.
\end{abstract}

\begin{abstract}
Measurements of pitch variations are performed over the twisted phases of three recent pure polar mesogens exhibiting reentrant polymorphism: $(\alpha) \mathrm{KN}_{\mathrm{re}}^{*} \mathrm{~S}_{\mathrm{A}} \mathrm{N}^{*} \mathrm{I} ;(\beta) \mathrm{KS}_{\mathrm{F}}^{*} \mathrm{~S}_{\mathrm{c}}^{*} \mathrm{~N}_{\mathrm{re}}^{*} \mathrm{~S}_{\mathrm{A}} \mathrm{N}^{*} \mathrm{I} ;(\gamma) \mathrm{S}_{\mathrm{A}}$ $\mathrm{N}_{\mathrm{re}}^{*} \mathrm{~S}_{\mathrm{Arc}} \mathrm{N}^{*} \mathrm{I}$. Numerous and precise values confirm pitch divergence near $\mathrm{S}_{\mathrm{A}}$, pitch divergence at each side of cholesteric phase when sandwiched between $S_{A}$ and $S_{A r e}$ phases. $S_{c}^{*}$ pitch keeps a finite value at $\mathrm{S}_{\mathrm{c}}^{*}-\mathrm{N}_{\mathrm{re}}^{*}$ and $\mathrm{S}_{\mathrm{F}}^{*}-\mathrm{S}_{\mathrm{c}}^{*}$ transitions. Direct measurements of pitch, performed by Grandjean-Cano method are confirmed by optical activity study : such comparison gives informations about birefringence variations.
\end{abstract}

\section{Introduction.}

In opposition to most of cholesteric mesophases, for which the helical pitch decreases with increasing temperature, the pitch of a reentrant cholesteric generally increases. Billard [1] puts in evidence the strong increase of the pitch near the $\mathrm{N}_{\mathrm{re}}^{*} \rightarrow \mathrm{S}_{\mathrm{A}}$ transition, from the observation of contact preparations between - a compound presenting a nematic reentrant mesophase and - a cholesteric mesogen. Chilaya [2] also measured the helical pitch divergence in reentrant and normal cholesteric phases of mixtures of nematics and optically active dopants, using Bragg diffraction on focal conic textures or selective reflexion spectra on planar textures.

We present here precise and detailed pitch variations measurements of the $\mathrm{N}_{\mathrm{re}}^{*}$ and $\mathrm{N}^{*}$ phases of three pure compounds, presenting the following phase sequences: $(\alpha) \mathrm{KN}_{\mathrm{re}}^{*} \mathrm{~S}_{\mathrm{A}} \mathrm{N}^{*} \mathrm{I} ;(\beta) \mathrm{KS}_{\mathrm{F}}^{*}$ $\mathrm{S}_{\mathrm{c}}^{*} \mathrm{~N}_{\mathrm{re}}^{*} \mathrm{~S}_{\mathrm{A}} \mathrm{N}^{*} \mathrm{I} ;(\gamma) \mathrm{KS}_{\mathrm{A}} \mathrm{N}_{\mathrm{re}}^{*} \mathrm{~S}_{\text {Are }} \mathrm{N}^{*} \mathrm{I}$. The $\mathrm{S}_{\mathrm{c}}^{*}$ phase of the $(\beta)$ compound is also studied.

\section{Studied compounds.}

The studied compounds are<smiles>CCC(C)[C@H](C)CCOc1ccc(C(=O)Oc2ccc(-c3ccc(C#N)cc3)cc2)cc1</smiles>

with the following phases sequences $\left({ }^{\circ} \mathrm{C}\right)$ :

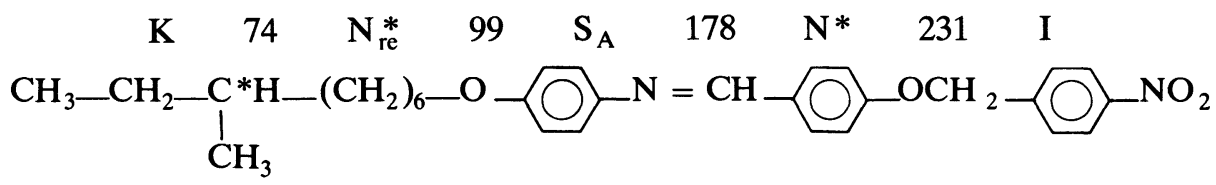


with

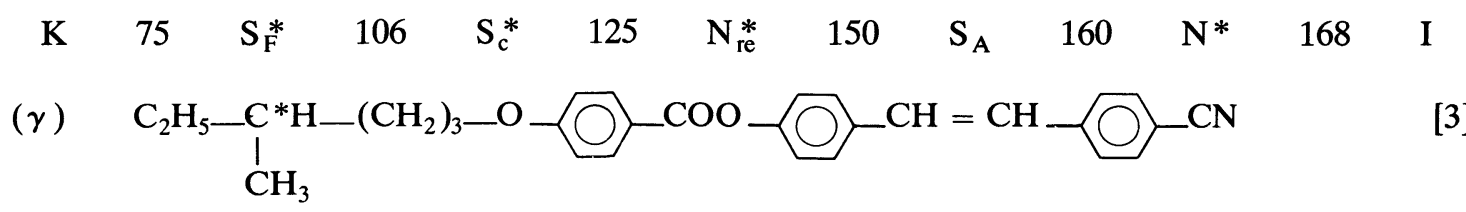

with

$$
\begin{array}{lllllllllll}
\mathrm{K} & 88 & \mathrm{~S}_{\mathrm{A}} & 112 & \mathrm{~N}_{\mathrm{re}}^{*} & 131 & \mathrm{~S}_{\text {Are }} & 217 & \mathrm{~N}^{*} & 275 & \mathrm{I}
\end{array}
$$

The properties of $\beta$ and $\gamma$ are expected to be more interesting because their $\mathrm{N}_{\text {re }}^{*}$ phases are situated between two smectic phases: $\mathrm{S}_{\mathrm{c}}^{*} \mathrm{~S}_{\mathrm{A}}$ for $\beta$ and $\mathrm{S}_{\mathrm{A}} \mathrm{S}_{\text {Are }}$ for $\gamma$.

\section{Principles of experimental methods.}

All measurements are performed on a polarizing microscope.

3.1 The Grandjean-Cano Texture. Direct MEASUREMENT OF THE PITCH. - The GrandjeanCano [6, 7] planar texture can be obtained in a cholesteric weak angle prism: the cholesteric is introduced between two glasses orienting the molecules at the surfaces in a unique direction perpendicular to the edge ; equidistant parallel defects appear at thicknesses $d_{k}=p / 4+k \frac{P}{2}$; they separate constant width steps in which the twist angle is $k \pi$. According to temperature variations, pitch variations induce a displacement of the Grandjean-Cano defects and a modification of their distance. So microscopic measurements of the steps width, associated with the angle of the prism, give the mean pitch value and its variation with the temperature.

3.2 THE APPARENT ROTATORY POWER IN GRANDJEAN-CANO SAMPLES. - The apparent rotatory power of cholesterics is given by the de Vries [8] expression :

$$
\Omega=-\frac{\pi}{4} \frac{\Delta n^{2} p}{\lambda^{2}\left(1-\lambda^{2} / n^{2} p^{2}\right)} .
$$

When the pitch is large $(p \gg \lambda)$ this expression can be simplified and the rotatory power is proportionnal to the ptich:

$$
\Omega \cong-\frac{\pi}{4} \frac{\Delta n^{2}}{\lambda^{2}} P
$$

This expression is not valid when the pitch grows and approches the Mauguin's limit $p_{\mathrm{M}}=\frac{2 \lambda}{\Delta n}$ [9]. The rotatory power then saturates slightly [10].

In Grandjean-Cano prism samples, measurements are done in the middle of the steps ; there only, the pitch gets its «natural » value $p$. Rotation of the analyser gives optical rotation $\theta_{k}$ in the $k$-th step ; thickness is $e_{k}=k P / 2$. So rotatory power is calculated as $\Omega=\theta_{k} /(k P / 2)$.

Optical rotation measurements need special care when pitch approaches Maugin's limit: ellipticity fluctuations of analysed light become important, reaching maximum values when rotation is close to $\left(l+\frac{1}{2}\right) \pi$; good extinctions with a linear analyser need to choose a $k$-th step where $\theta$ is close to $l \pi$.

For our three compounds, (1) is sufficient. So pitch temperature dependence can be controlled by rotatory power temperature dependence, if the material birefringence is constant in the studied phase.

3.3 THE ROTATORY POWER OF PLANAR DROPS. The rotation of the polarisation plane can be measured on flat planar drops [10] for instance. All measurements are performed at the same point of the drop. If the free surface shape of the drop does not change with temperature, the thickness remains constant. So optical rotation variations are representative of the rotatory power variations. Temperature pitch dependence can then be controlled or completed like in the previous section.

\section{Experimental studies.}

4.1 Generalities. - The slides are first rubbed on a felt support impregnated with diamond paste diluted in alcohol (dimension of the grains $\cong 1 \mu \mathrm{m}$; 40 go and return). The slides are then carefully cleaned with alcohol; and finally wiped with a soft paper, respecting the same direction as the rubbing one. The cleanness of the slides is very important to insure the planar texture : indeed the studied compounds are polar and exhibit a clear tendency to homeotropy, giving undesirable finger prints texture.

The lower glass is a $75 \times 20 \mathrm{~mm}$ slide. The upper glass is a fragment $(30 \times 5 \mathrm{~mm})$. One edge of the upper glass is lifted up by a thin glass slide $(150 \mu \mathrm{m})$; the angle of the prism is then about $0.2-0.3^{\circ}$. A little drop of product is placed near the edge of the prism. The sample is introduced in the 
$\mathrm{FP}_{2}$ Mettler stage, at a temperature where the substance is cholesteric. The drop melts and the prism is filled by capillarity.

\subsection{THE COMPOUND $\alpha: \mathrm{KN}_{\mathrm{re}}^{*} \mathrm{~S}_{\mathrm{A}} \mathrm{N}^{*} \mathrm{I}$.}

4.2.1 Reentrant cholesteric phase. - The introduction temperature is close to $92^{\circ} \mathrm{C}$; there, the mesophase fluidity enables an easy filling of the prism. On the other hand, $\mathrm{N}_{\mathrm{re}}^{*} \mathrm{~S}_{\mathrm{A}}$ transition is far enough to avoid pretransitional effects, and it is easy to obtain 6-10 regular Grandjean steps. Then, a slow temperature decrease enables to approach the $\mathrm{K}-\mathrm{N}_{\mathrm{re}}^{*}$ transition within one degree ; the displacement of the Grandjean lines often eliminates some defects in the parallelism of the lines (if necessary, it may be useful to do temperature cycles). It is now possible to observe and measure the lines distance temperature dependence over the whole $\mathrm{N}_{\mathrm{re}}^{*}$ range when the temperature grows, and to measure simultaneously optical rotations in the middle of some steps.

4.2.2 High temperature cholesteric phase. - Near the $\mathrm{N}_{\mathrm{re}}^{*}-\mathrm{S}_{\mathrm{A}}$ transition, the first step $(k=0)$ invades the whole preparation, giving a perfectly planar $\mathrm{S}_{\mathrm{A}}$. This texture is stable if the temperature increase speed is sufficient (if not, the $S_{A}$ becomes rapidly homeotropic). When homeotropy is avoided, the Grandjean texture reappears after the $S_{A}-N^{*}$ transition. The pitch decrease can be observed if the temperature variation is fast. But, in this high temperature cholesteric phase, the Grandjean lines rapidly disappear, a finger print texture appears; the measure of the pitch variations is then impossible.
For this reason, the high temperature phase is studied in the following way : a new preparation is built and introduced in the stage at the studied temperature. The Grandjean texture generally lasts 10 to $30 \mathrm{~s}$; this is sufficient for only one measurement of the steps width ; for another temperature, it is necessary to built another preparation.

To avoid the dispersion resulting from studied cells multiplicity, the rotatory power variations are observed on a single drop for which the quality of the planar texture remains generally good over the whole $\mathrm{N}^{*}$ temperature range. (This drop is deposited on a rubbed glass.)

4.2.3 Results. - For the $\mathrm{N}_{\mathrm{re}}^{*}$ phase, the pitch clearly increases and diverges at the $\mathrm{S}_{\mathrm{A}}$ transition (Fig. 1). The optical study confirms pitch measurements (Fig. 2) and gives the left-handedness of the structure. In the $\mathrm{N}^{*}$ phase the pitch diverges near the $\mathrm{S}_{\mathrm{A}}$, decreases and gets a quasi constant value over a wide temperature range. The dispersion is due to the multiple studied samples.

The rotatory power is susceptible to correct the direct measurements of the pitch near the $S_{A}$ phase. The strong decrease of the rotatory power beyond $190^{\circ} \mathrm{C}$ is due to the birefringence decrease near liquid phase.

\subsection{THE COMPOUND $\beta: \mathrm{KS}_{\mathrm{F}}^{*} \mathrm{~S}_{\mathrm{c}}^{*} \mathrm{~N}_{\mathrm{re}}^{*} \mathrm{~S}_{\mathrm{A}} \mathrm{N}^{*} \mathrm{I}$.}

4.3.1 Cholesteric phases. - The sample is introduced in the stage in the middle of the $\mathrm{N}_{\text {re }}^{*}$ temperature range $\left(135^{\circ}\right)$; then cooled to $125^{\circ} \mathrm{C}$ and heated. For this second compound $\beta$, the tendency to homeotropy is less than for $\alpha$. It is possible to study

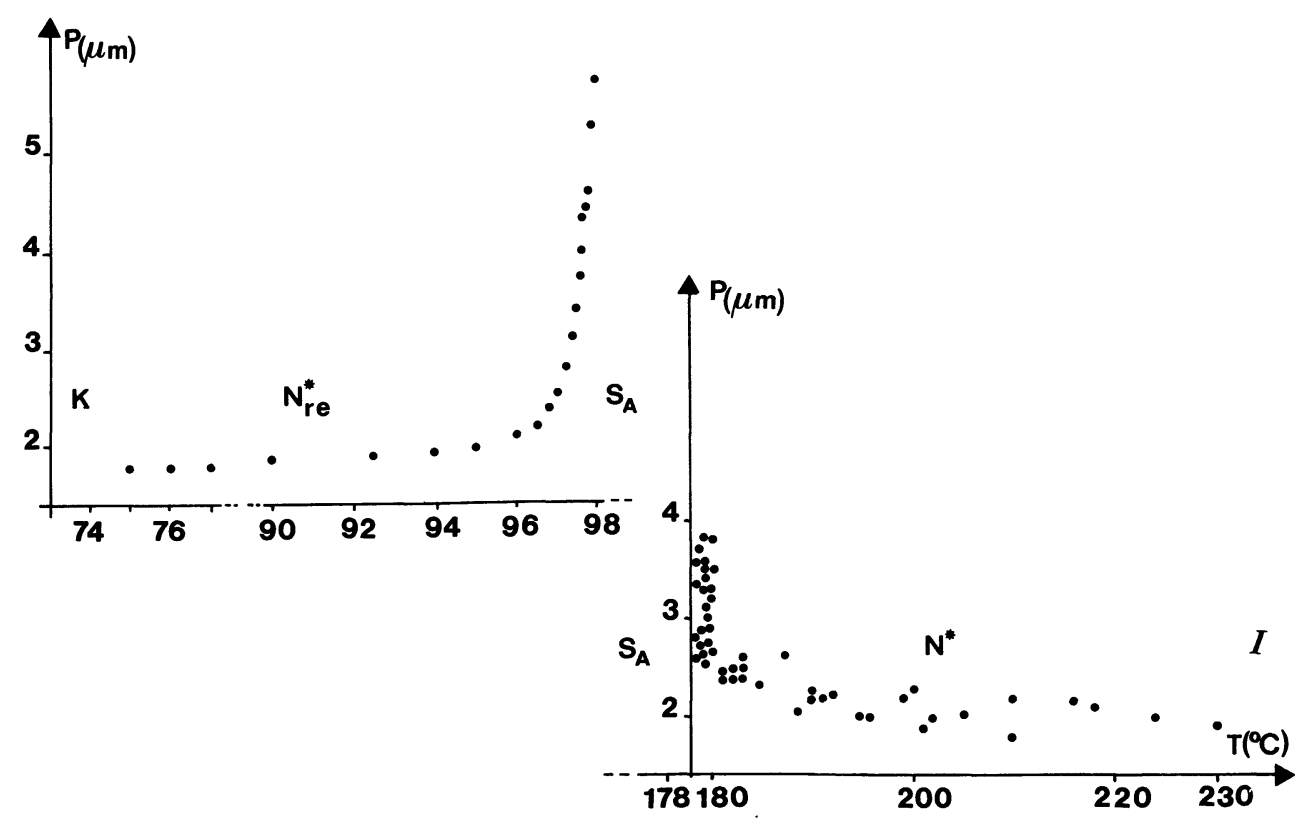

Fig. 1. $-\alpha$ Compound (described in Sect. 2) : variations of the pitch versus temperature. 

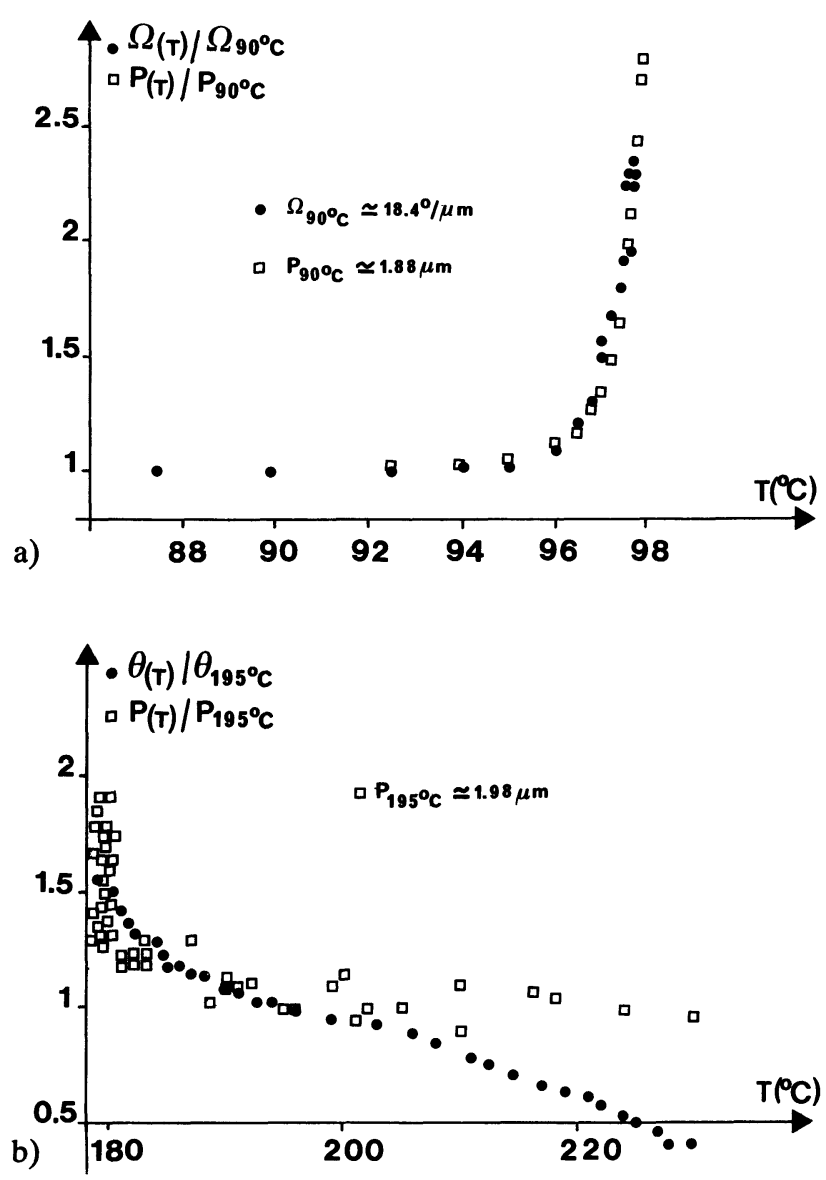

Fig. 2. $-\alpha$ Compound (described in Sect. 2) : comparison of reduced rotation and reduced pitch variations. a) In $\mathrm{N}_{\mathrm{re}}^{*}$ phase, the birefringence is constant. b) The birefringence falls near liquid state.

the two $\mathrm{N}^{*}$ phases with the same sample provided that the $S_{A}$ phase is rapidly crossed.

Generally, after more or less time, the sample finally looses his Grandjean texture and finger-prints appear near the $\mathrm{N}^{*} \mathrm{I}$ transition. This is irreversible and Grandjean lines no more reappear in the $\mathrm{N}^{*}$ phases when the temperature is decreased. However, an interesting phenomenon then occurs, in the $\mathrm{S}_{\mathrm{c}}^{*}$ phase : cooling the $\mathrm{N}_{\mathrm{re}}^{*}$ in the finger-print texture gives regular Grandjean-Cano $2 \pi$ disclinations in the $S_{c}^{*}$ phase, allowing the $S_{c}^{*}$ pitch study. Indeed, two conditions are here simultaneously satisfied: the homeotropy tendency orients the screw axis of the $S_{c}^{*}$ phase perpendicular to the sample plane, and the rubbing of the glasses orients the projection of the director at the interfaces. So the total twist angle is $2 k \pi$, leading to $2 \pi$ disclination lines, equidistant and parallel to the edge of the prism. Regions with $(2 k+1) \pi$ lines can also be observed.

4.3.2 The $\mathrm{S}_{\mathrm{c}}^{*}$ phase. - The Grandjean-Cano geometry in the $S_{c}^{*}$ phase can also be obtained directly : rubbed glasses are covered with a surfactant favouring the homeotropy (HTAB for example). The sample is introduced in the stage in the $\mathrm{S}_{\mathrm{c}}^{*}$ temperature range $\left(121^{\circ} \mathrm{C}\right)$. The GrandjeanCano pseudo-homeotropic texture of the $S_{c}^{*}$ is very stable over the whole $S_{c}^{*}$ range. The steps width variations give the values of the $S_{c}^{*}$ pitch.

In the $\mathrm{S}_{\mathrm{F}}^{*}$ phase, the Grandjean-Cano lines are still visible, but no more move when the temperature changes.

Notice endly that in the $S_{c}^{*}$ phase, the indicatrix is not perpendicular to the screw axis, but titled at the «tilt angle» $\theta$. The extraordinary index, for the waves propagating along the screw axis is :

$$
n_{\mathrm{e}}^{\prime}=\left(\frac{\cos ^{2} \theta}{n_{0}^{2}}+\frac{\sin ^{2} \theta}{n_{\mathrm{e}}^{2}}\right)^{-1 / 2} ;
$$

the birefringence $\Delta^{\prime} n=n_{\mathrm{e}}^{\prime}-n_{0}$, is then weaker than $\Delta n=n_{\mathrm{e}}-n_{0}$, and the apparent rotatory power $\left(\Omega \cong-\frac{\pi}{4} \Delta^{\prime} n^{2} \frac{P}{\lambda^{2}}[11]\right)$ is much weaker than in the $\mathrm{N}^{*}$ phases. So, the preparation in the $\mathrm{S}_{\mathrm{c}}^{*}$ phase is not coloured, and the Grandjean-Cano steps are not very visible.

4.3.3 Results. - The figure 3 gives the variations of the pitch in the three twisted phases. In the $\mathrm{S}_{\mathrm{c}}^{*}$ phase the pitch increases slowly with the temperature increase. After the $S_{c}^{*}-N_{r e}^{*}$ transition, the pitch is about $4 \mu \mathrm{m}\left(2 \mu \mathrm{m}\right.$ in the $\left.S_{c}^{*}\right)$, first decreases slowly, and rapidly increases and diverges near the $\mathrm{N}_{\mathrm{re}}^{*} \mathrm{~S}_{\mathrm{A}}$ transition. In the $\mathrm{N}^{*}$ phase, the pitch diverges at the $S_{A}$ transition, and decreases.

The comparison of pitch and rotatory power variations reveals a weak decrease of the birefringence in the $\mathrm{N}_{\mathrm{re}}^{*}$ (Fig. 4a) phase : $\Delta n=0.23$ at $125^{\circ} \mathrm{C}$ and 0.20 at $148^{\circ} \mathrm{C}$. In the $\mathrm{N}^{*}$ phase the birefringence strongly decreases when approaching the liquid phase : $\Delta n=0.19$ at $159^{\circ} \mathrm{C}$ and 0.13 at $167^{\circ} 7$. In the three twisted mesophases, the right rotatory power indicates a right-handed helix.

4.4 The COMPOUND $\gamma: \mathrm{KS}_{\mathrm{A}} \mathrm{N}_{\mathrm{re}}^{*} \mathrm{~S}_{\mathrm{Are}} \mathrm{N}^{*} \mathrm{I}$. - For the $\gamma$ compound the tendency to homeotropy is as strong as for the first one $\alpha$. The experiment can still be performed with two samples.

For the reentrant cholesteric phase, the sample is introduced at $120^{\circ} \mathrm{C}$, as far as possible of the $\mathrm{S}_{\mathrm{A}}$ transitions. The sample is cooled to $113^{\circ} \mathrm{C}$ near the $S_{A}$ transition, and then heated over the whole $\mathrm{N}_{\mathrm{rc}}^{*}$ range. The Grandjean texture is generally stable and all measurements are performed with one sample. When crossing the $S_{\text {Are }}$ phase, the texture becomes homeotropic, and the Grandjean texture does not appear in the high temperature $\mathrm{N}^{*}$.

In the $\mathrm{N}^{*}$ phase, the Grandjean texture is obtained only if the sample is introduced in the stage near the clarification point, when the mesophase has a sufficient fluidity. Pitch variations over the $\mathrm{N}^{*}$ phase are then obtained on cooling with the same sample. 


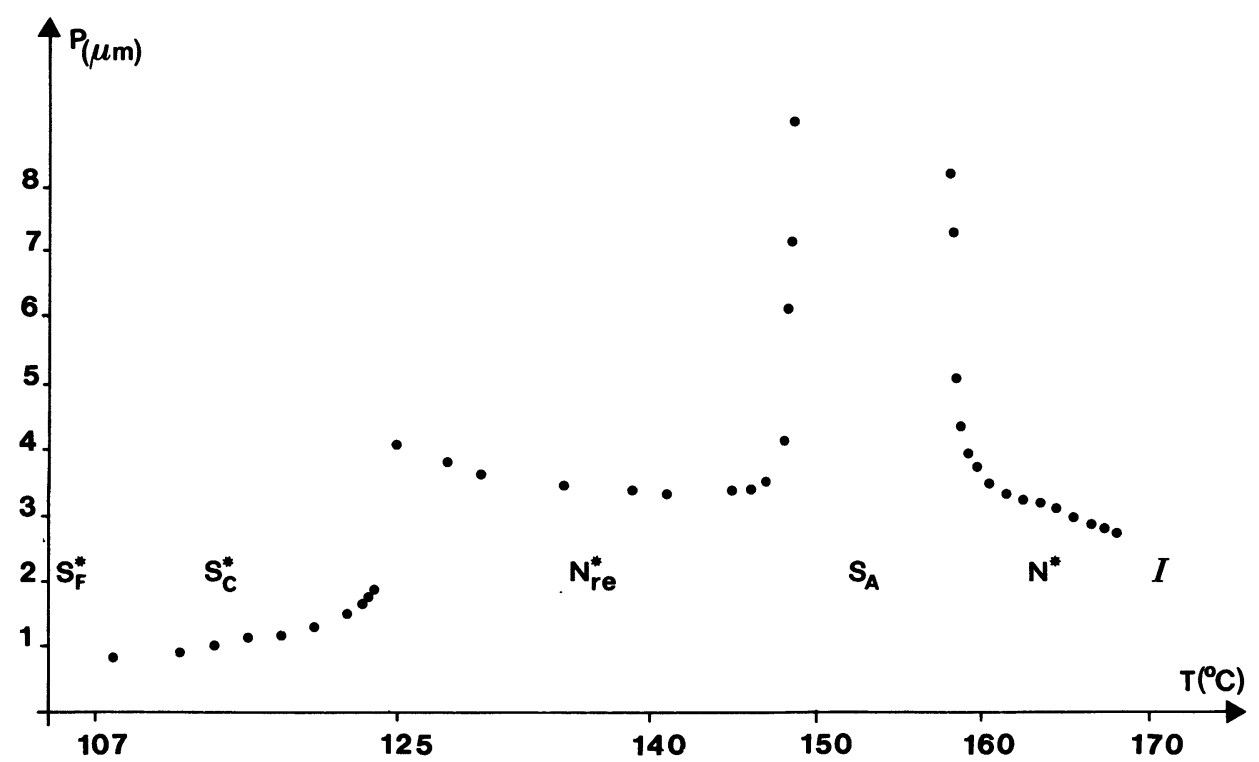

Fig. 3. $-\beta$ compound (described in Sect. 2 ) : variations of the pitch versus temperature.

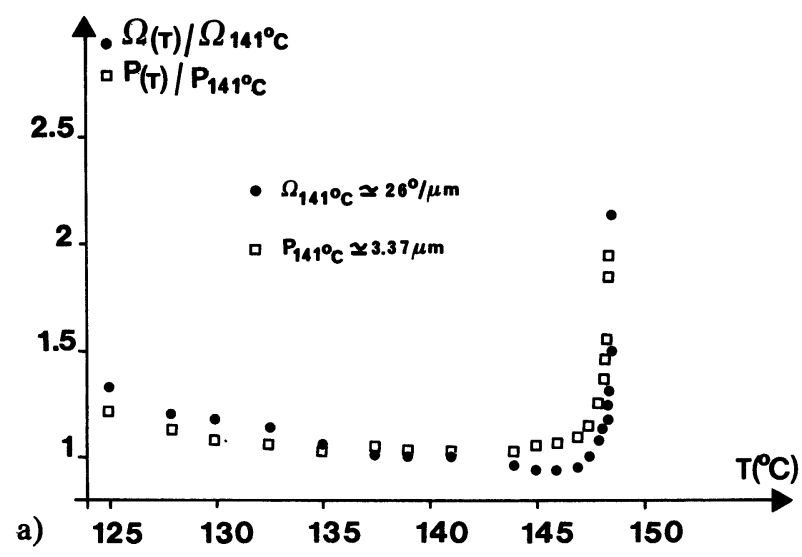

b)

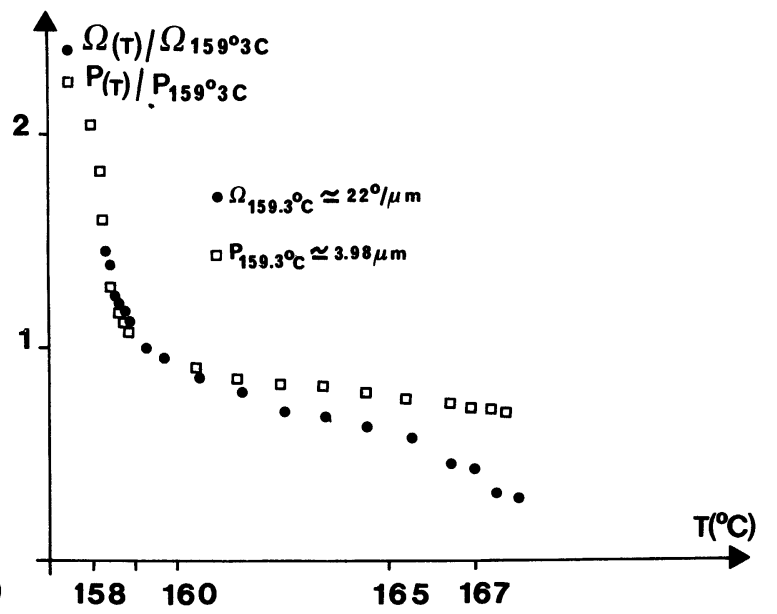

Fig. 4. - $\beta$ compound (described in Sect. 2 ) : comparison of reduced rotatory power and reduced pitch variations.

a) The birefringence is quasi constant in the $\mathrm{N}_{\mathrm{re}}^{*}$ phase.

b) The birefringence falls near liquid state.

REVUE DE PHYSIQUE APPLIQUÉE. - T. 23, N`3, MARS 1988
Near the $S_{\text {Are }}$ phase, irrevocable finger-points often appear.

We mention at last another difficulty : the stilbene group is very light-sensitive ; if the sample is lightened by the white light of the microscope, the configuration of the molecules change from trans to cis ; in the lightened place, the thermodynamic, the structural and the optical characters change; the reentrant $\mathrm{N}^{*}$ phase can even disappear if the exposure is too long. This difficulty can be solved by reduction of the incident light flow with an interferentiel filter ( $5640 \AA$ ), filter besides necessary for the rotatory power study ; a slight alteration is still visible : at the end of a series of experiments, the transition occurs at temperatures different from those measured by calorimetry [5, 4] (Sect. 2) : $127^{\circ} \mathrm{C}$ instead of $131^{\circ} \mathrm{C}$ for $\mathrm{N}_{\mathrm{re}}^{*} \rightarrow \mathrm{S}_{\text {Are }}$ and $223^{\circ} \mathrm{C}$ instead of $217^{\circ} \mathrm{C}$ for $\mathrm{S}_{\text {Are }} \leftarrow \mathrm{N}^{*}$ (Figs. 5 and 6).

Results. - The figure 5 gives the pitch variations in the two cholesteric phases; the reentrant phase exhibits two divergences of the pitch, near the $\mathrm{S}_{\mathrm{A}}-\mathrm{N}_{\mathrm{re}}^{*}\left(113^{\circ} \mathrm{C}\right)$ and $\mathrm{N}_{\mathrm{re}}^{*}-\mathrm{S}_{\mathrm{Are}}\left(127^{\circ} \mathrm{C}\right)$ transitions; the pitch is minimum near $120^{\circ} \mathrm{C}$.

The rotatory power variations confirm the pitch measurements (Fig. 6a) and gives the sign, left, of the helicity. In the $\mathrm{N}^{*}$ phase, the pitch diverges near the $\mathrm{S}_{\mathrm{A}}$ phase $\left(223^{\circ} \mathrm{C}\right)$ and is quasi constant from $235^{\circ} \mathrm{C}$ to $275^{\circ} \mathrm{C}$. The rotatory power variations (Fig. 6b) reveal a strong decrease of the birefringence above $240{ }^{\circ} \mathrm{C}$.

\section{Conclusions.}

Precise and detailed measurements of the twist are performed on three pure compounds presenting 

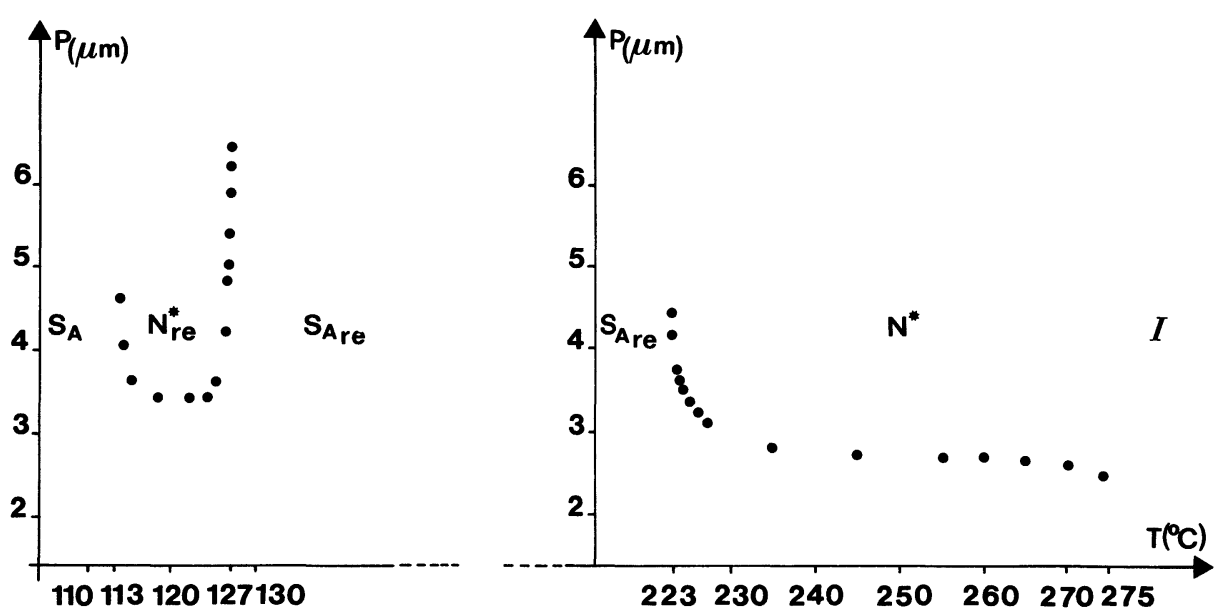

Fig. 5. $-\gamma$ compound (described in Sect. 2) : variations of pitch versus temperature.

a)

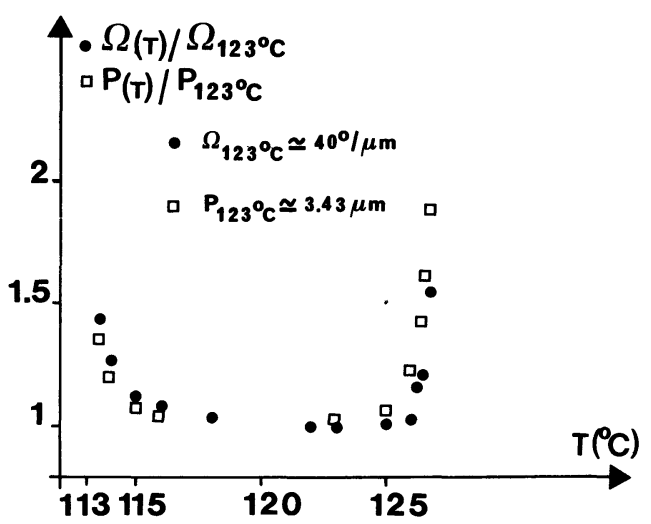

b)

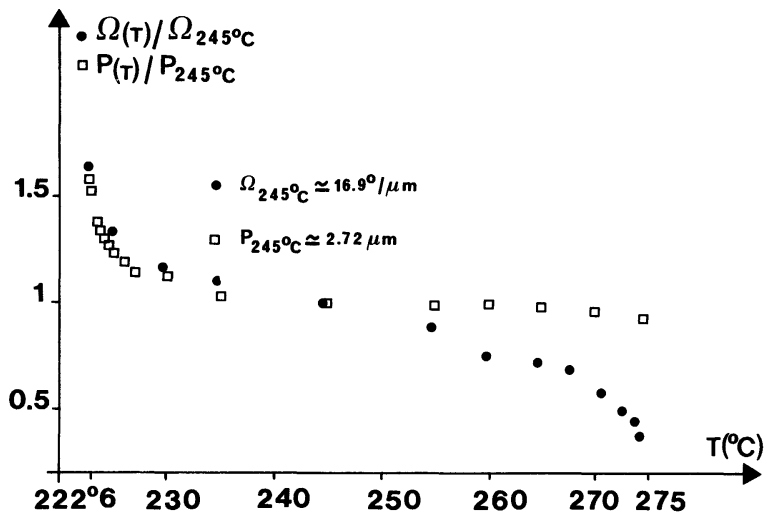

Fig. 6. $-\gamma$ compound (described in Sect. 2) : comparison of reduced rotatory power and reduced pitch variations. a) The birefringence is quasi constant in the $\mathrm{N}_{\text {re }}^{*}$ phase.

b) The birefringence falls near liquid state. different sequences of phases, and having a reentrant cholesteric phase. In the high temperature cholesteric phase, the pitch is infinite near the $S_{A}-N^{*}$ transition, and gets a quasi constant value up to the liquid phase. Rotatory power measurements reveal a strong decrease of the birefringence.

In the rentrant cholesteric phase of the $\alpha$ compound, (sequence $\mathrm{KN}_{\mathrm{re}}^{*} \mathrm{~S}_{\mathrm{A}} \mathrm{N}^{*} \mathrm{I}$ ) the pitch is quasi constant far from the $S_{A}$, and diverges near the $\mathrm{N}_{\mathrm{rc}}^{*}-\mathrm{S}_{\mathrm{A}}$ transition. For $\boldsymbol{\beta}$ (sequence $\mathrm{KS}_{\mathrm{F}}^{*} \mathrm{~S}_{\mathrm{c}}^{*} \mathrm{~N}_{\mathrm{re}}^{*} \mathrm{~S}_{\mathrm{A}} \mathrm{N}^{*} \mathrm{I}$ ), the pitch slowly decreases from a limite value at the $S_{c}^{*}-N_{\text {re }}^{*}$ transition, shows a minimum, and increases to diverge at the $\mathrm{N}_{\mathrm{re}}^{*}-$ $\mathrm{S}_{\mathrm{A}}$ transition.

For $\gamma\left(\mathrm{KS}_{\mathrm{A}} \mathrm{N}_{\mathrm{re}}^{*} \mathrm{~S}_{\mathrm{Are}} \mathrm{N}^{*} \mathrm{I}\right)$, the pitch has two divergences and a minimum. For the three products, similar values of pitch appear in the two cholesteric phases.

The pitch measurements are performed on prismatic cells with Grandjean-Cano planar texture. Except for the $\mathrm{N}^{*}$ phase of $\beta$, a unique sample is used for the whole temperature range. The rotatory power is studied to control or complete the pitch measurements and to give the sense of the helix (left for $\alpha, \gamma$; right for $\beta$ ).

The $\mathrm{S}_{\mathrm{c}}^{*}$ phase of $\beta$ is studied by an original method: the strong tendency to be homeotropic (which is a serious disadvantage to get Grandjean planar texture in the $\mathrm{N}^{*}$ phases) leads to a pseudohomeotropic texture in the $S_{c}^{*}$ phase, with regular $2 \pi$ disclinations permitting the $S_{c}^{*}$ pitch measurements. 


\section{References}

[1] Billard, J., C. R. Hebd. Séan. Acad. Sci. Paris 292 II (1981) 881-2.

[2] Chilaya, G. S., Destrade, C., Elashvili, Z. M., IVCHENKo, S. P., Lisetski, L. N., NGUYeN HuU Tinh, Vinokur, K. D., J. Phys. Lett. 46 (1985) 75-8.

[3] Destrade, C., Nguyen Huu Tinh, Malthète, J., Mol. Cryst. Liq. Cryst., 127 (1985) 273-82.

[4] Malthète, J., Nguyen HuU Tinh, Destrade, C., N. J. Chim. 9 (1985) 557-60.

[5] Nguyen Huu Tinh, Gasparoux, H., Babeau, A., Destrade, C., 6th Liquid Crystals Conference of Socialist Countries, August 26-30, 1985, Halle, G.D.R.
For synthesis of the core see : NGUYEN HUU TINH, Gasparoux, H., Destrade, C., Mol. Cryst. Liq. Cryst. 123 (1985) 271-293.

For the chiral chain see ref. [4] of the present article. [6] Grandjean, F., C. R. Hebd. Scéan. Acad. Sci. Paris 172 (1921) 71-4.

[7] Cano, R., Bull. Soc. Fr. Min. Crist. 91 (1968) 20-7.

[8] De VRIES, Hl., Acta. Cryst. 4 (1951) 219-26.

[9] Mauguin, Ch., Bull. Soc. Fr. Min. Crist. 34 (1911) 6-15.

[10] Isaert, N., Berthault, J. P., Billard, J., J. Optics 11 (1980) 17-41.

[11] Parodi, O., J. Phys. Colloq. France 36 (1975) C1325-26. 